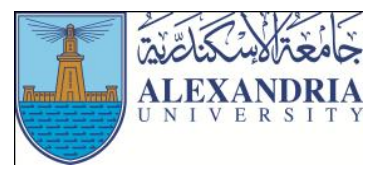

\title{
The Effect of Using Specific Exercises by Tools on Learning Some of the Basic Skills for Basketball Beginners Under 14 Years Old
}

\author{
Alshimaa Abdel fatah Alkhfif ${ }^{1}$ \\ ${ }^{1}$ Lecturer, of the theories and applications of sports collective and racket sports Department of physical Education College, \\ Sadat City University, Egypt.
}

\begin{abstract}
:
Through the work of the researcher teaching and teaching basketball to the students of the Faculty of Physical Education and what the skills needed from the compatibility of the motor and development of perception and difficult to develop after the age of 14 years so the researcher turned to apply the program to the basketball beginners at the school sports Menoufia, which becomes more influential and during which uses alternative tools during The application of specific exercises aimed at the development of the sense of kinetics of young people using some of the tools that are similar in composition in terms of the composition of motor performance of strength and speed, and the time course of strength as well as the direction of muscle work with those movements Lead in the game, those exercises away The performance of the traditional way constitutes a basis for the development of skills for rapid movement, and more impact on the accuracy of muscle movement and compatibility, as well as improved reaction kinetic and that which is lacking during the stages of education and training of youth within clubs.
\end{abstract}

In light of this, the researcher saw the attempt to design an educational program using specific exercises by tools to find out how it affects the learning of some basic skills in basketball.

Introduction and research problem:

B asketball games are characterized by the rapid pace and continuous transition between attack and defense throughout the game, requiring all players to perform basic skills at a level so close that each player to meet the needs of his position on the court, which requires increased attention to prepare the teams in all aspects of physical, skill, tacticing and psychological. (4: 29)

The specific exercises are the movements that are similar in their kinetic composition with the movements performed by the player during the sports competition in terms of strength, speed, time course of strength, and the direction of muscular action with the movements performed in the performance of the technical, and therefore is a direct means to prepare the main player in terms of Motor compatibility and follow the path and direction of motor performance. (5: 18)

And the special exercises of the training that work to achieve the requirements to be accessed directly to obtain the optimal form of motor performance, and is the closest means to prepare the player and develop his ability in the type of activity practiced. (2: 88.89)
Al-Shaimaa Alkhfif (2014) states that kinesthetic perception through specific exercises using some aids is important when acquiring a new kinetic skill, If the young person does not realize the movement or skill required of him correctly and accurately, he will not be able to perform or perform it accurately, The skill of the motor helps to sense the place where it leads, and the extent required to constrict the muscles of the body different, and the directions of the body parts in the vacuum, which helps the young to control the movements of his body so that performance appears expressive, and the movement efficiently and smoothly. (3: 15)

The availability of tools is one of the main elements of success in the training module. The high level of performance of individuals and the achievement of the objectives of the activity is related to the availability of the necessary tools and their availability to the positive participation and increase the motor perception of the player as well as improving the motor and skill performance, as well as increasing the focus of attention and understanding and stimulate their mental activity and accept To train with desire and enthusiasm. (7: 117) 
Atef Maher (2012) states that the training aids, if they are better selected and developed programs, increase the motivation of the players towards learning. It also works to improve the technical aspects and the development of the physical aspects associated with the skill performance and create training conditions similar to the conditions of the game. Training and dealing with these situations is easier and work on the economy in the time allocated to education and training in the case of combining physical performance and skill at the same time and increase the fun and excitement of players and the economy in the preparation of players used in training and therefore Player time increases in practice and training. (4: 19)

And through the work of the researcher teaching and learning basketball to the students of the Faculty of Physical Education and what the skills needed from the compatibility of the motor and development of perception and difficult to develop after the age of 14 years so the researcher turned to apply the program to the basketball beginners at the school sports Menoufia, which becomes more influential and during which uses alternative tools during The application of specific exercises aimed at the development of the sense of kinetics of young people using some of the tools that are similar in composition in terms of the composition of motor performance of strength and speed, and the time course of strength as well as the direction of muscle work with those movements Lead in the game, those exercises away The performance of the traditional way constitutes a basis for the development of skills for rapid movement, and more impact on the accuracy of muscle movement and compatibility, as well as improved reaction kinetic and that which is lacking during the stages of education and training of youth within clubs.

In light of this, the researcher saw the attempt to design an educational program using specific exercises by tools to find out how it affects the learning of some basic skills in basketball.

\section{Research objectives:}

\section{This research aims at:}

1- Designing an educational program using specific exercises by tools and identifying their effect on:

- The skills variables of the experimental research group.

- Physical variables of the experimental research group.

2- Identify the rates of improvement of the physical and skill tests of the research group.

\section{Research hypotheses:}

1- There are statistically significant differences between the mean (pre - post) of the research group in the physical variables in favor of the post - measurement.

2- There are statistically significant differences between the mean (pre - post) of the research group in the skills variables in favor of the post - measurement.

\section{Terms used:}

\section{Specific exercises:}

"It is a momentary or staged exercise that starts from the same skillful performance and details, and includes all the moments of actual performance". (5: 33)

\section{Research procedures:}

\section{First, the research methodology:}

The researcher used the experimental method due to its relevance to the nature of this study, It used one of the experimental designs was the experimental design for one group using pre and post measurement.

\section{Second, the research community:}

The research society was chosen by the intentional method of basketball beginners in the first grade preparatory school at the girls school in Shebin El Koum in Menoufia Governorate, And the strength of the research community (105) beginners.

\section{Third, the research sample:}

The sample of the research was chosen by the intentional method of (30) beginners, (10) beginners were chosen from the research community representing the primary sample and the first grade students for the 2016/2017 academic year, and the total number of exploratory sample (20) beginners (10) junior students from the third grade, (10) beginners from the research community and outside the basic sample to conduct scientific transactions (Believe - stability).

The researcher's choice of the research sample is due to the following reasons:

1-All beginners in one stage of growth and the same age.

2-the conditions of the work of the researcher as a trainer for the sample and thus easy to apply them.

3-availability of all material resources available at the school, which helps to achieve the objectives of the research.

The homogeneity of the sample: 
The researcher found the homogeneity of the sample of the research as a whole (30) beginners to make sure that they occur under the average curve in the variables (age height - weight), as shown in Table (1).
The researcher also found the homogeneity of the research sample in the skills and physical variables of the sample of the research sample, as shown in Table (2).

Table (1)

Statistical characterization of the sample individuals in the variables "Age - Height - Weight" $(\mathrm{n}=30)$

\begin{tabular}{|c|c|c|c|c|c|c|}
\hline Variables & measruing unit & mean & Median & Mode & St.d & skewness \\
\hline Age & Year & 13.06 & 13.20 & 13.20 & 0.45 & -0.34 \\
\hline Height & C.m & 1.51 & 1.52 & 1.52 & 0.45 & -0.27 \\
\hline weight & K.g & 50.03 & 50.40 & 46.90 & 3.28 & -0.59 \\
\hline
\end{tabular}

Table (1) shows that coefficients of torsion of research Height - Weight) which indicates the coherence of the sample are between $(+3,-3)$ in the variables of (Age - sample.

Table (2)

Statistical characterization of individuals sample in the Tests used $(n=40)$

\begin{tabular}{|c|c|c|c|c|c|c|}
\hline variables & Measure unit & mean & Median & Mode & St.d & skewness \\
\hline Sprint 30m & sec & 5.15 & 5.11 & 5.15 & 0.39 & 0.70 \\
\hline Agility & $\mathrm{sec}$ & 8.56 & 8.61 & 8.67 & 0.22 & -0.42 \\
\hline Numbered circuits & $\mathrm{sec}$ & 5.03 & 5.01 & 4.84 & 0.21 & 1.10 \\
\hline Throw tennis balls & point & 13.00 & 13.00 & 14.00 & 1.38 & 0.27 \\
\hline Accuracy & point & 14.80 & 14.00 & 12.00 & 2.75 & 0.35 \\
\hline Dribble & sec & 18.41 & 18.57 & 17.20 & 1.89 & -0.08 \\
\hline Chest pass & point & 9.18 & 9.45 & 10.00 & 1.42 & 0.33 \\
\hline Free throw & point & 0.42 & 0.47 & 0.50 & 0.32 & 0.04 \\
\hline Lay-up shot right & point & 1.14 & 1.00 & 1.00 & 0.61 & -0.12 \\
\hline Lay-up shot lift & point & 0.81 & 1.00 & 1.00 & 0.54 & -0.67 \\
\hline
\end{tabular}

Table (2) shows the homogeneity of the research sample in Physical and technical skills tests, as the skewness of research sample are between $(+3,-3)$ in the variables.

\section{Third, tools and means of data collection:}

The researcher based on the collection of information and data related to this research to the means and tools considered by the researcher to meet the following conditions:

- Be easy to implement and have metering devices.

- Be effective in diagnosing specific aspects of research.

- To meet the scientific standards (Believe - stability).

\section{Personal interviews:}

The researcher designed questionnaire forms of experts in the field of basketball and the number of (3) experts Attachment (1) to determine:

- Physical and skill tests that are suitable for the research sample.

- Contents of the proposed program. Attachment (4)

\section{2. tools and equipment used in the research:}

The following tools and devices were used:

- Electronic balance for measuring weight, Resistometer for measuring length, Asics, sling, Medical balls less than $1 \mathrm{~km}$, Basketball court, Legal basket balls, Wall and chalk, Stopwatch for measuring time, measuring tape, wall mounted grading, spongy mattresses, cones, tennis balls, lists of $50 \mathrm{~cm}$ height.

\section{Forms Search:}

- Recording data on individuals search forms:

The researcher designed forms to record the measurements of the research so as to have the simplicity and ease of registration for the collection and scheduling of data in order to be processed statically as follows:

-Registration form for measurements of variables (age height - weight).

-An individual form to record the tests of the skills and physical.

-A combined form to record the beginner's measurements in physical and skill tests. 


\section{Fourth: Scientific transactions used for the tests:}

\section{Believe skill and physical tests: -}

The Believe of the skills and physical tests and were calculated by calculating the Believe of the differential by applying them to two groups of 10 beginner's The first group represents the Third-grade players (the distinctive group) while the second group represents the beginners from the research community and outside the core sample(the undistinctive group), On Tuesday 19/9/2016 at the sports school Shebin El Koum, and the following tables illustrate the differences between the two groups (distinctive and non-distinctive) in the skills and physical tests.

Table (3)

Significance of differences between the distinctive and indistinctive Groups In used tests (N $1=$ N 2 = 10)

\begin{tabular}{|c|c|c|c|c|c|c|c|}
\hline \multirow{2}{*}{ variables } & \multirow{2}{*}{$\begin{array}{c}\text { Measurement } \\
\text { unit }\end{array}$} & \multicolumn{2}{|c|}{ distinctive group } & \multicolumn{2}{|c|}{ indistinctive group } & \multirow{2}{*}{$\begin{array}{c}\text { Means } \\
\text { difference }\end{array}$} & \multirow{2}{*}{ 'T' Test } \\
\hline & & mean & s.d & mean & s.d & & \\
\hline Sprint $30 \mathrm{~m}$ & $\mathrm{sec}$ & 4.62 & 0.25 & 5.58 & 0.24 & -0.96 & -8.72 \\
\hline Agility & $\mathrm{sec}$ & 6.28 & 0.35 & 8.44 & 0.15 & 2.16 & 1.88 \\
\hline Numbered circuits & $\mathrm{sec}$ & 4.20 & 0.15 & 5.06 & 0.24 & -0.87 & -9.68 \\
\hline Throw tennis balls & point & 17.00 & 1.05 & 12.50 & 1.78 & 4.50 & 6.88 \\
\hline Accuracy & point & 22.60 & 1.71 & 15.80 & 2.04 & 6.80 & 8.06 \\
\hline Dribble & $\mathrm{sec}$ & 11.42 & 1.69 & 16.27 & 1.87 & 4.85 & 5.62 \\
\hline Chest pass & point & 19.73 & 1.32 & 10.51 & 1.89 & 9.22 & 8.38 \\
\hline Free throw & point & 2.62 & 0.67 & 0.54 & 0.49 & 2.08 & 6.77 \\
\hline Lay-up shot right & point & 3.44 & 0.81 & 1.32 & 0.62 & 2.12 & 7.94 \\
\hline Lay-up shot lift & point & 2.83 & 0.76 & 1.14 & 0.57 & 1.69 & 5.53 \\
\hline
\end{tabular}

The value of "T" Driven at the level $(0.05)=(1.73)$

Table (3) shows statistically significant differences between the two distinct and Undistinctive groups in the previous tests. The calculated values of $\mathrm{T}$. are greater than their tabular value at the level of (0.05) indicating that these tests can distinguish between individuals, Means the Believe of these tests.

\section{The stability of skill and physical tests:}

The coefficient of stability of the skills and physical tests were found using the test-retest method on a sample of
(10) beginners from the research community and outside the basic sample (undistinctive group), The researcher considered the results of the tests for the Believe of the undistinctive group as the first application, and re-applied the tests under the same conditions and the same instructions after (7) days of the first application, On Tuesday 26/9/2016 at the sports school in Shebin El Koum, and the following table explain the correlation coefficients between the first and second Implementation. 
Table (4)

Reliability coefficient For the tests used ( $N=10$ )

\begin{tabular}{|c|c|c|c|c|c|c|c|}
\hline \multirow{2}{*}{ variables } & \multirow{2}{*}{$\begin{array}{c}\text { Measurement } \\
\text { unit }\end{array}$} & \multicolumn{2}{|c|}{ Implementation first } & \multicolumn{2}{|c|}{ Implementation second } & \multirow{2}{*}{$\begin{array}{c}\text { Means } \\
\text { difference }\end{array}$} & \multirow{2}{*}{ correlation } \\
\hline & & mean & s.d & mean & s.d & & \\
\hline Sprint $30 \mathrm{~m}$ & $\mathrm{sec}$ & 5.58 & 0.24 & 5.53 & 0.26 & 0.05 & 0.85 \\
\hline Agility & $\mathrm{sec}$ & 8.44 & 0.15 & 8.34 & 0.19 & 0.10 & 0.74 \\
\hline Numbered circuits & $\mathrm{sec}$ & 5.06 & 0.24 & 4.95 & 0.27 & 0.11 & 0.94 \\
\hline Throw tennis balls & point & 12.50 & 1.78 & 12.90 & 2.03 & -0.40 & 0.72 \\
\hline Accuracy & point & 15.80 & 2.04 & 16.30 & 1.34 & 0.50 & 0.66 \\
\hline Dribble & $\mathrm{sec}$ & 16.27 & 1.87 & 16.11 & 1.78 & 0.16 & 0.66 \\
\hline Chest pass & point & 10.51 & 1.89 & 11.50 & 1.43 & 0.99 & 0.63 \\
\hline Free throw & point & 0.54 & 0.49 & 0.66 & 0.32 & 0.12 & 0.71 \\
\hline Lay-up shot right & point & 1.32 & 0.62 & 1.57 & 0.49 & 0.25 & 0.67 \\
\hline Lay-up shot lift & point & 1.14 & 0.57 & 1.23 & 0.46 & 0.09 & 0.68 \\
\hline
\end{tabular}

The value of " $R$ " Driven at the level $(0.05)=(0.632)$

Table (4) shows that the calculated " $t$ " value in all previous tests indicates that the value of $t$ is a statistical function, This indicates a correlation between the first and second applications and thus the stability of the tests.

\section{Fifthly: Steps to design the education program: -}

\section{Steps Design for the educationl Program:}

The researcher developed the educational program using specific exercises with tools to teach some basic skills to beginners. In light of this, the researcher put the program on the following bases and steps:

- that its content is consistent with the objective of the program.

- The contents of the program should challenge their abilities so as to stimulate their motivation to learn.

- Provide the right place and facilities to implement the program.

- Taking into account security and safety factors when applied.

- Ensure that the program achieves the thrill and excitement factor.

- The program is characterized by simplicity and diversity.
- Consider gradation from easy to hard.

\section{Program design:}

In light of the references of scientific references and previous studies, the proposed program was designed according to the following steps:-

\section{a- Defining the objective of the proposed program:}

The proposed program aims to know the effect of the use of specific exercises with tools on the level of performance of some basic skills of the research sample.

\section{b- Educational content of the program:}

The program included the specific exercises with tools within the applied part. 132 exercises were selected.

\section{- Time distribution of the proposed program:-}

The researcher prepared the educational program to include (10) weeks, four units a week, that is, the program includes (40) educational units, The Unit time is 90 Min (educational and applied part), While the specific exercises are applied to the research tools during the application part of the unit and its time is $40 \mathrm{~min}$, The program includes (4) educational skills to master and improve performance, The table shows the time distribution of the proposed program. 
Table (5)

Time distribution of the proposed educational program

\begin{tabular}{|c|c|c|c|}
\hline S & Content & \multicolumn{2}{|c|}{ Time distribution } \\
\hline 1 & Number of weeks & \multicolumn{2}{|c|}{40} \\
\hline 2 & Number of units per week & \multicolumn{2}{|c|}{40} \\
\hline 3 & Number of educational units as all & 10 min Warm Up & 5 min Cool Down \\
\hline \multirow{2}{*}{4} & Application time per unit & 35 min Explanation and model & 40 min application \\
\cline { 2 - 4 } & Total time of the program & \multicolumn{2}{|c|}{3600 min } \\
\hline 5 & Sixth: The choice of assistants: & Affer the end of the period specified for the
\end{tabular}

The researcher selected two assistants from her schooltrained colleagues. They were introduced to the research aspects, objectives in terms of measurement requirements, how to perform physical and skill tests, and knowledge about any queries they face during the research.

\section{Seventh: Steps search application:}

\section{1. per measurements:}

The researcher conducted the tribal measurement to find the homogeneity of the research sample in the variables (age - height - weight) and conduct the tribal measurement of physical and skill variables on Sunday 17/9/2016.

\section{Implementation of the basic experience:}

The program was implemented from Sunday 2/10/2016 to Thursday $8 / 12 / 2016$ and the duration of the program was 10 weeks Includes (40) educational units during the application part of the unit.

\section{3. post measurements:}

After the end of the period specified for the implementation of the basic experiment, the researcher carried out the post-measurement of the research group of physical and skill variables on Sunday 11/12/2016, The researcher took into consideration that the measurement is carried out under the same conditions in which the per measurement was carried out.

\section{Ninth: statistical treatments:}

Statistical treatment consisted in:

-Descriptive statistics "measures of central tendency standard deviation sprains transactions"

- The correlation coefficient to calculate the stability of skill and knowledge tests.

- Test "T" (T. test).

- Spearman correlation coefficient.

Presentation and discussion of the results:

Table (6)

Significance of differences between the mean of two measurements ( per - post )

In the used tests For the experimental group $(\mathrm{N}=10)$

\begin{tabular}{|c|c|c|c|c|c|c|c|c|}
\hline \multirow{2}{*}{ variables } & \multirow{2}{*}{$\begin{array}{c}\text { Measure } \\
\text { unit }\end{array}$} & \multicolumn{2}{|c|}{ pre measurement } & \multicolumn{2}{|c|}{ Post measurement } & \multirow{2}{*}{$\begin{array}{c}\text { Means } \\
\text { difference }\end{array}$} & \multirow{2}{*}{ 'T' Test } & \multirow{2}{*}{$\begin{array}{l}\text { Improvement } \\
\text { ascriptions }\end{array}$} \\
\hline & & mean & s.d & mean & s.d & & & \\
\hline Sprint $30 \mathrm{~m}$ & $\mathrm{sec}$ & 5.45 & 0.23 & 4.76 & 0.25 & 0.69 & 2.89 & $12.66 \%$ \\
\hline Agility & $\mathrm{sec}$ & 8.54 & 0.15 & 7.14 & 0.12 & 1.40 & 6.62 & $16.39 \%$ \\
\hline Numbered circuits & sec & 5.10 & 0.24 & 4.26 & 0.20 & 0.84 & 8.45 & $16.47 \%$ \\
\hline Throw tennis balls & point & 12.80 & 1.32 & 17.30 & 0.95 & 4.50 & 8.77 & $35.16 \%$ \\
\hline Accuracy & point & 15.00 & 2.00 & 24.80 & 1.93 & 9.80 & 11.14 & $65.33 \%$ \\
\hline Dribble & $\mathrm{sec}$ & 17.47 & 1.76 & 12.37 & 1.62 & 5.10 & 6.12 & $29.19 \%$ \\
\hline Chest pass & point & 10.88 & 1.75 & 17.52 & 1.49 & 6.64 & 7.67 & $61.03 \%$ \\
\hline Free throw & point & 0.47 & 0.51 & 2.63 & 0.64 & 2.16 & 7.25 & $\% \leq 09.01$ \\
\hline Lay-up shot right & point & 1.28 & 0.64 & 3.20 & 0.77 & 1.92 & 6.44 & $150.00 \%$ \\
\hline Lay-up shot lift & point & 0.94 & 0.46 & 2.56 & 0.78 & 1.62 & 5.89 & $172.34 \%$ \\
\hline
\end{tabular}

The value of "T" Driven at the level $(0.05)=(1.833)$

Table (6) shows statistically significant differences between the (pre-post) measurements in favor of the postmeasurement of the research group in the physical and skill variables. The calculated value $(\mathrm{t})$ was higher than the tabular values at a significant level (0.05). 
Figure (1)

Indication of differences between the mean (pre - post) measures for used test

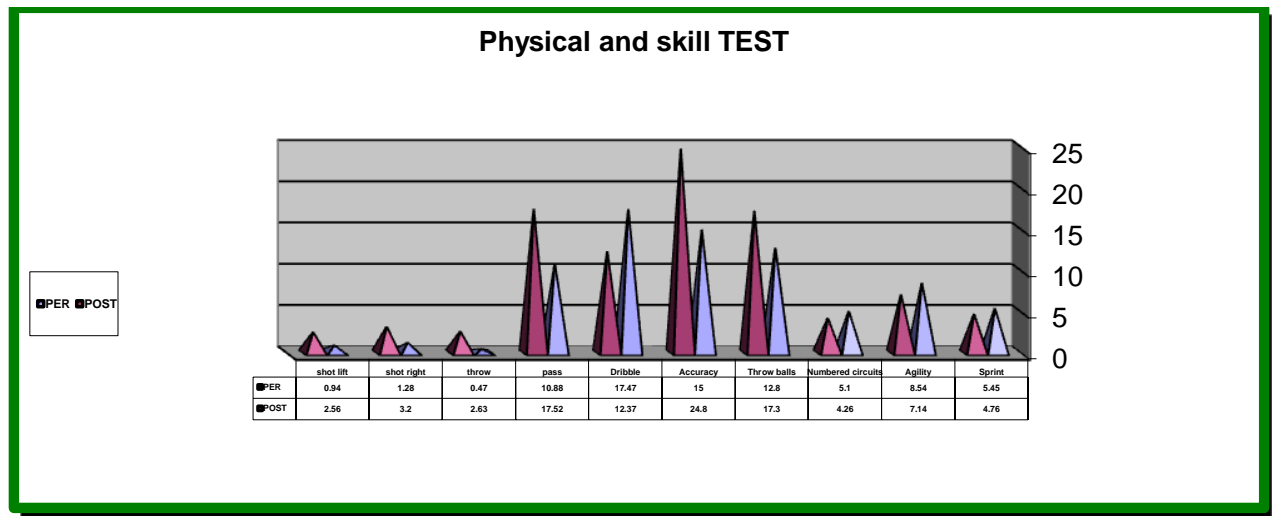

\section{Second, discuss the results:}

The researcher discusses the results obtained from the data of the research group and statistical treatments using the reference frame and previous studies as follows:

\section{- Discussion of the results of the first and second hypotheses:}

Table (6) shows that there are statistically significant differences between the mean of the pre and the post measurements of the research group where the value of $(t)$ of the table $(1,88)$ was less than the value $(t)$ calculated at a significant level (0.05) The results showed the development of the skillful performance of the dribble skill, the chest pass, and free throw, and the lay-up skill, This result was agreed with the study of Atef Al-Adawi 2012 (4), which showed the effectiveness of the proposed program in developing the skills under discussion.

The results showed that the difference between the results of the physical components of speed, reaction, agility, eye and foot coordination, eye and hand coordination, accuracy and this result was agreed with the study of Saha Abboud 2009 (9), Said Ghareeb 2004 (8) to That the speed, coordination, accuracy and agility of the most important physical abilities associated with the performance of basic skills as agreed results with the study of Ali Ajmi 2001 (1), which showed the effectiveness of the proposed program and its impact on physical requirements.

The researcher also considers that the specific exercises by tools are directly related to the technical performance of the motor skills that affect and affect him. Thus, it can be said that the high level of sensory perception is an indicator of the high level of skill performance of the player, which reflects the importance of sensory perception, On the ability of the player to change the status of the body requires the performance in terms of form and installation and the connection of motor and motor safety and control the effort, while maintaining the overall balance commensurate with the nature of performances of different skills to be done at a pace appropriate and full compatibility between the two devices Nerve and musculoskeletal so that skill performance can be achieved to the best level of performance. Therefore, specific exercises by tools must be built with the teaching and training of motor skills in a uniform range.

Mohamed Abdel Rahim, 1992 (6) agrees that dribble and the lay-up skill is one of the most and difficult skills. It requires a great deal of agility, speed, speed of reaction time and accuracy, It also requires a great deal of concentration for a long time and perception and endurance.

Thus, the first and second hypotheses, each of which states that there are statistically significant differences between the mean measurement (pre - post) of the research group in physical and skill variables for the post measurement.

\section{Conclusions:}

Through the nature of this study and the sample and the methodology used and the results of the statistical analysis in the scope of this research to the researcher reached the following conclusions:

- The educational program using the specific exercises by tools positively affect the level of physical and skill through the application of the program for a period of (10) weeks.

- Based on the results of the research results that there is a strong correlation between the development of some 
physical qualities and skill level of performance, the higher the physical level, the better the improvement in the level of skill performance.

\section{Recommendations:}

In light of the conclusions based on the nature of the study, the sample, the methodology used and the results of the statistical analysis, the researcher was able to identify the recommendations that benefit the work in the field of juniors education in basketball as follows:

1-To direct the results of this study and the program used and the steps to implement it to the workers in the field of educating juniors in basketball to benefit from these results.

2. The program should include different models of specific exercises by tools, which will have a significant impact on the progress of juniors levels.

3. Conduct similar studies using tools on different skills in basketball sport.

4-Conduct similar studies using some exercises in other collective and individual activities.

\section{References:}

1- Ali Mohammed Al Ajmi: Effect of a proposed training program for some of the ballistic offensive skills on the performance of basketball players, unpublished Ph.D research, Faculty of Physical Education for Boys, Tanta University, 2001.

2- Alsayed Abdel Maqsoud: Mathematical Training Considerations The Basic Aspects of the Training Process, Hassana Office, Cairo, 1999.
3- Alshimaa Abdel fatah Alkhfif: Suggested training program for to developing the kinesthetic perception and its effect on some basket ball skills, unpublished $\mathrm{Ph} . \mathrm{D}$ research, Faculty of Physical Education, Sadat city University, 2014.

4- Atef Maher Al-Adawi: The effect of a proposed training program to develop the speed and accuracy of the correction of jumping to basketball originator using a training tool, unpublished master research, Faculty of Physical Education, Sadat city University, 2012.

5- Essam El Din Abdel Khaliq: Sports training (theories and applications), edition 12, Al-Ma'aref Establishment, Cairo, 2005.

6- Mohamed Abdel Rahim Ismail: Aperception of the times and distances and their relationship to learning basketball skills for juniors under 12 years, Master research, unpublished, Faculty of Physical Education for Boys, Alexandria University, 1992.

7- —: Basketball Applications Process (1) Attack, Second Edition, Al Ma'aref Establishment, 2007.

8- Said Ghareeb Mohammed: The effect of a proposed training program on some the kinesthetic perception and accuracy shoot for a basketball junior under 14 years, unpublished master research, Faculty of Physical Education for Boys, Zagazig University, 2004.

9- Suha Abbas Abboud: Sense perception - spatial dynamics and its relationship to the level of learning some of the skills of basketball, published research, Journal of Sports Science, the first issue, Baghdad, University of Mustansiriya, 2010 